\title{
Penggunaan Sistem Arduino Menggunakan RFID untuk Keamanan Kendaraan Bermotor
}

\author{
Subastian Manurung ${ }^{* 1}$, Iin Parlina ${ }^{2}$, Fitri Anggraini ${ }^{3}$, Dedy Hartama ${ }^{4}$, Jalaluddin ${ }^{5}$ \\ 1,2,3,4,5 Teknik Informatika, STIKOM Tunas Bangsa Pematangsiantar, Indonesia \\ Email: ${ }^{1}$ subastianmanurung@gmail.com, ${ }^{2}$ iin@ amiktunasbangsa.ac.id, ${ }^{3} \mathrm{ftranggraini850@} \mathrm{gmail.com,}$ \\ ${ }^{4}$ dedyhartma@yahoo.com, ${ }^{5}$ jalaluddin@ stikomtb.ac.id
}

\begin{abstract}
Abstrak
Dengan semakin pesatnya perkembangan zaman, tingkat kriminalitas juga semakin tinggi, seperti pencurian, perampokan, pemerkosaan dan lain lain, untuk kasus curanmor di Indonesia sangat tinggi, oleh karena itu maka penulis membuat sebuah penelitian terkait Pengamanan Sepeda Motor dengan menggunakan e-KTP dimana penelitian ini adalah sistem kendali dan RFID untuk alat scanning kartu pada sepeda motor. Alat ini dibuat untuk menggantikan fungsi kunci konvensional yang digunakan oleh sepeda motor kebanyakan. Scanner dapat digunakan dalam jarak kurang $10 \mathrm{~cm}$ dari e-KTP yang akan digunakan dan e-KTP sudah terkonfigurasi terlebih dahulu dalam database. Sehingga secara otomatis mesin sepeda motor akan menyala dan motor dapat digunakan. Adapun tujuan penggunaan scanning e-KTP adalah meminimalisir adanya pencurian dan meningkatkan keamanan sepeda motor serta menambah daya tarik sepeda motor itu sendiri. Dalam pembuatan system pengamanan ini penulis menggunakan istem Arduino yang terintegrasi dengan RFID. Hasil dari penelitian ini untuk membantu Pengendara agar tidak perlu terlalu khawatir akan keamanan kendaraan sehingga memberikan rasa aman dalam berkendara.
\end{abstract}

Kata kunci: Arduino, Keamanan Kendaraan Bermotor, RFID

\begin{abstract}
With the rapid development of the times, the crime rate is also getting higher, such as theft, robbery, rape and others, for the theft case in Indonesia is very high, therefore the author makes a study related to Motorcycle Security using e-KTP where this research is a control system and RFID for card scanning devices on motorcycles. This tool is made to replace the conventional lock function used by most motorcycles. The scanner can be used within $10 \mathrm{~cm}$ of the e-KTP to be used and the e-KTP has been pre-configured in the database. So that the motorcycle engine will automatically turn on and the motor can be used. The purpose of using e-KTP scanning is to minimize theft and increase motorcycle security and increase the attractiveness of the motorcycle itself. In making this security system the author uses the Arduino system which is integrated with RFID. The results of this study are to help motorists not have to worry too much about the safety of the vehicle so as to provide a sense of security in driving.
\end{abstract}

Keywords: Arduino, Motor Vehicle Safety, RFID

\section{PENDAHULUAN}

Perkembangan teknologi radio frequency (RF) semakin meningkat dan banyak digunakan di berbagai macam jenis aplikasi, contohnya pada media elektronik, radio, telepon seluler, radar, dan automatic identification system.

Kriminalitas pencurian sepeda motor sudah sering kali terjadi disekitar kita. Adapun modus pencurian yang mereka lakukan seperti menggunakan kunci palsu atau kunci $\mathrm{T}$ dan bahkan menggunakan cairan kimia untuk merusak penutup lubang kunci pada sepeda motor. Tidak hanya itu tingkat pengendara sepeda motor dibawah umur juga semakin meningkat. Karena lalainya pengawasan orang tua terhadap anak bahkan anak itu sendiripun berani mencuri kunci sepeda motor orang tua mereka. 
Dalam kasus ini penulis merancang sebuah sistem keamanan pada sepeda motor untuk mencegah pencurian sepeda motor dan yang terutama mencegah anak dibawah umur untuk tidak mengendarai sepeda motor tanpa seizin orang tua mereka dengan menggunakam pemanfaatan teknologi RFID. Radio Frequency Identification atau RFID ialah sebuah perangkat telekomunikasi data yang memanfaatkan gelombang radio untuk pertukaran data antara pembaca dengan sebuah Electronic tag yang dihubungkan pada sepeda motor (Isyanto et al., 2019).

Dengan memanfaatkan sensor pada RFID pengaktifan sepeda motor tidak hanya sebatas menggunakan kunci konvensional akan tetapi juga menggunakan e-KTP sebagai Register tag yang sudah didaftarkan pada sistem sebagai konfirmasi bahwasanya KTP tersebut adalah pemilik dari sepeda motor.

Sehingga sistem ini dapat meminimalisir pencurian karena tidaksemua orang dapat menghidupkan sepeda motor tersebut dan penyalahgunaan sepeda motor terhadap anak dibawah umur. Berdasarkan latar belakang yang telah penulis jabarkan maka pada penelitian ini, penulis tertarik untuk mengambil judul "Penggunaan Sistem Arduino Menggukan RFID untuk Keamanan Kendaraan Bermotor".

\subsection{Identifikasi Otomatis}

Identifikasi otomatis dilakukan dengan pembuatan sistem interlock atau penguncian dengan menggunakan e-KTP sebagai pengenal yang didaftarkan pada register tag di dalam database yang kemudian dilakukan uji scanning atau mengidentifikasi e-KTP pada RFID.sehingga program dapat mengenal kepemilikan dari kartu tersebut (Ariesta Adhitama Satya Negara, Ufi Najib, 2017).

Identifikasi menggunakan e-KTP dilakukan agar mikrokontroler dapat merespon kartu pengenal tersebut sebagai pemilik dari sepeda motor yang sudah dihubungkan dengan RFID dan Arduino. Ketika e-KTP cocok atau dikenal oleh sistem maka pemilik sepeda motor dapat mengaktifkan atau menghidupkan mesin sepeda motor.

\subsection{Arduino Uno}

David Cuartielles dan Massimo Banzi merupakan penemu dari Arduino. Arduino merupakan sebuah papan elektronik dengan mikrokontroler berukuran kecil serta dilengkapi dengan sejumlah pin yang digunakan sebagai penghubung komunikasi antara arduino dengan perangkat alat elektronik lainnya. Arduino Uno R3 tipe pertamanya diluncurkan pada tahun 2011. R3 sendiri memiliki arti revisi ketiga dari pengembangan arduino Uno (Baehaki, 2017).

Kemajuan Teknologi Mikrokontroler saat ini sudah sampai pada penggunaan Mikrokontroller dengan berbagai platform open source seperti Arduino Uno. Untuk mengaktifkan Arduino Uno hanya langsung di hubungkan ke komputer dengan kabel USB atau menggunakan adaptor AC ke DC serta menggunakan baterai. Untuk dayanya (Abimanyu et al., 2021).

Papan mikrokontroler arduino R3 dilengkapi dengan penghubung USB yang membantu menghubungkan arduino dengan PC guna melakukan pemrograman atau menuliskan perintah-perintah kedalam prosessor mikrokontroler. Arduino juga dapat diprogram dengan menggunakan ISP. Memiliki 14 pin digital yang digunakan sebagai input dan output serta dengan 6 pin pin analog yang setiap pin analognya memiliki resolusi sebesar 10 bit.

Bentuk Arduino Uno dapat di lihat pada gambar di bawah ini:

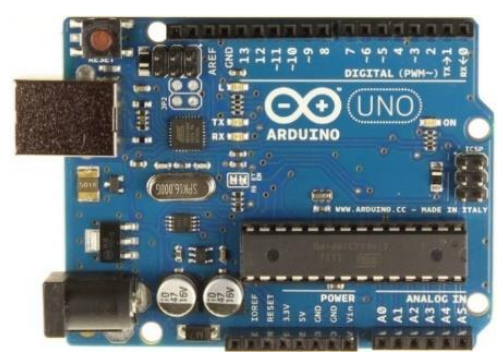

Gambar 1. Arduino Uno 


\subsection{RFID}

RFID atau Radio Frequency Identification merupakan sebuah perangkat yang memanfaatkan gelombang radio untuk mentransmisikan sebuah identitas yang dapat berupa sebuah nomor unik, barcode, sidik jari dan objek lainnya misalnya kartu. RFID memiliki keunggulan daripada perangkat pengenal elektronik lainnya seperti kartu magnetis dan barcode (Isyanto et al., 2019).

RFID (Radio Frequency Identification) adalah sistem komunikasi nirkabel yang memanfaatkan gelombang radio untuk melakukan prose pembacaan data yang terletak dalam tag RFID. Tag RFID umumnya berbentuk seperti kartu atm, kartu kredit maupun bentuk lainnya. Secara khusus teknologi RFID biasanya menggunakan medan elektromagnetik untuk dapat berkomunikasi dengan tag RFID (Mulya et al., 2021).

RFID digunakan sebagai alat mengidentifikasi sebuah objek misalnya kartu pengenal atau KTP dimana sensor membaca data berupa kode atau garis unik pada kartu tersebut. Data dikirimkan dari RFID menuju mikrokontroler untuk disesuaikan apakah data tersebut sudah terdaftar pada register tag atau belum.

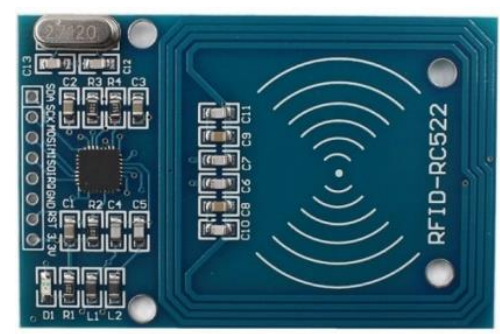

Gambar 2. RFID

\subsection{Relay}

Relay adalah Saklar (Switch) yang dioperasikan secara listrik dan merupakan komponen Electromechanical (Elektromekanikal) yang terdiri dari 2 bagian utama yakni Elektromagnet (Coil) dan Mekanikal (seperangkat Kontak Saklar/Switch). Relay menggunakan Prinsip Elektromagnetik untuk menggerakkan Kontak Saklar sehingga dengan arus listrik yang kecil (low power) dapat menghantarkan listrik yang bertegangan lebih tinggi (Saleh \& Haryanti, 2017).

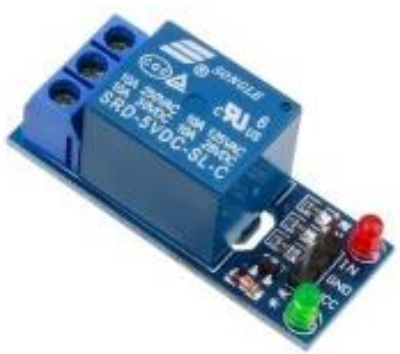

Gambar 3. Relay

\subsection{Kabel Jumper}

Kabel jumper merupakan kabel elektrik yang digunakan untuk menguhubungkan antara komponen elektronik yang ada tanpa perlu melakukan solder karena disetiap ujungnya sudah memiliki konektor atau pin. Konektor yang digunakan untuk menusuk disebut male connector sedangkan konektor yang ditusuk disebut female connector. Adapun 3 jenis konektor pada kabel jumper yaitu male to male, female to female dan male to female. 


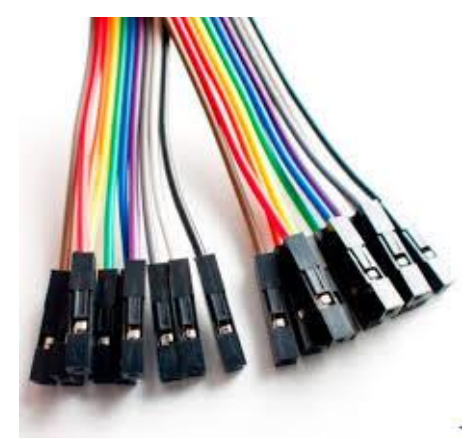

Gambar 4. Kabel Jumper

\subsection{Program Arduino IDE}

Arduino IDE adalah perangkat lunak yang digunakan untuk memprogram arduino dari pc. IDE sendiri berasal dari singkatan Integrated Development Enviroenment yang memiliki arti sebagai lingkungan yang terintegrasi dalam sebuah pengembangan.Arduino. IDE menggunakan bahasa pemrograman JAVA yang disertai dengan library $\mathrm{C} / \mathrm{C}++$ yang memudahkan operasi input dan output.

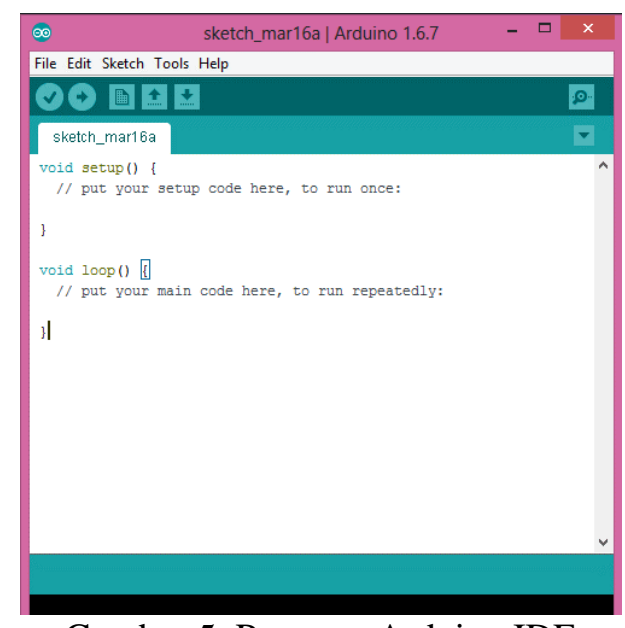

Gambar 5. Program Arduino IDE

Pada arduino terdapat IC mikrokontroler yang sudah disertai dengan Bootloader yang memiliki fungsi sebagai kompiler antara PC dan mikrokontroler. Karena mikrokontroler tidak memahami bahasa tingkat tinggi maka dari itu diperlukannya compiler sebagai penerjemah dari bahasa tingkat tinggi menjadi bahasa biner yang hanya dimengerti oleh mikrokontroler.

\section{METODE PENELITIAN}

Metode penelitian ini merangkum tentang bagaimana cara sistematis yang digunakan oleh peneliti dengan maksud menghasilkan jawaban yang dapat diterima atas apa yang menjadi pertanyaan pada objek penelitian atau upaya untuk mengetahui sesuatu dengan rangkaian sistematis

Pada penelitian ini membahas tentang rancang bangun alat pengamanan kendaraan bermotor menggunakan e-KTP dan RFID berbasis arduino, yang perancangannnya meliputi perangkat keras (hardware) dan perangkat lunak (software).

\subsection{Rancangan Penelitian}

Dalam merancang sistem alat pengamanan kendaraan bermotor menggunakan e-KTP dan RFID berbasis arduino, penulis membuat beberapa tahap perancancangan, mulai dari pengambilan data sampai dengan pengolahan yang akan dibuat sehingga hasil outputnya lebih jelas. 
Gambar rancangan penelitian dapat dilihat pada gambar berikut.

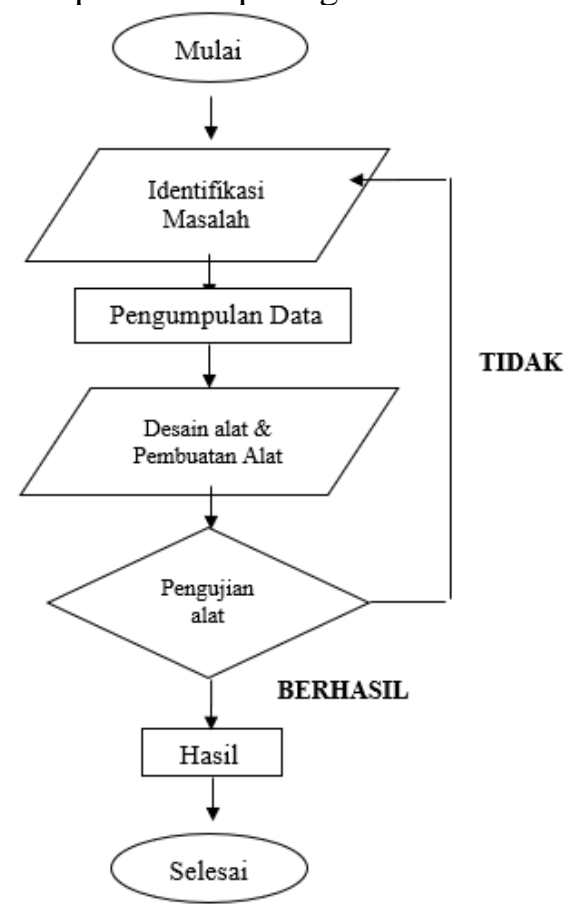

Gambar 6. Rangkaian Penelitian berikut:

Penjelasan flowchart penelitian yang dibuat penulis seperti pada gambar di atas adalah sebagai

1. Identifikasi Masalah

Pengenalan suatu masalah dan tahap awal dalam proses penelitian permasalahan penelitian ini yaitu meminimalisir pencurian dan mencegah terjadinya kecelakaan kendaraan bermotor anak dibawah umur.

2. Pengumpulan Data

Data pada penelitian ini diperoleh dari rumah rumah, dan lingkungan masyarakat dengan melihat banyaknya kejadian pencurian kendaraan bermotor.

3. Pengolahan Data

Pada langkah ini data-data yang sudah di dapat dari studi identifikasi masalah dan pengumpulan data yang kemudian di olah untuk menyelesaikan permasalahan yang ditemukan.

4. Studi Literatur

Metode pengumpulan data yang menggunakan beberapa jurnal sebagai referensi untuk penulis.

5. Observasi

Metode pegumpulan data dengan mengamati kendaraan bermotor yang umumnya digunakan masyarakat yang masih tergolong tidak aman.

6. Pembuatan Alat

Selanjutnya adalah merancang sebuah alat yang dapat menyeleseaikan permasalahan yang dialami.

\subsection{Perancangan Perangkat Keras}

Dalam meringankan perancangan sistem ini maka akan memakai blok diagram untuk tahapan awal dalam proses pembuatannya, dimana blok diagram ini digunakan untuk menampilkan bagaimana cara kerja sistem ini dilakukan secara umum. Sistem rangkaian dapat dilihat pada gambar dibawah ini. 


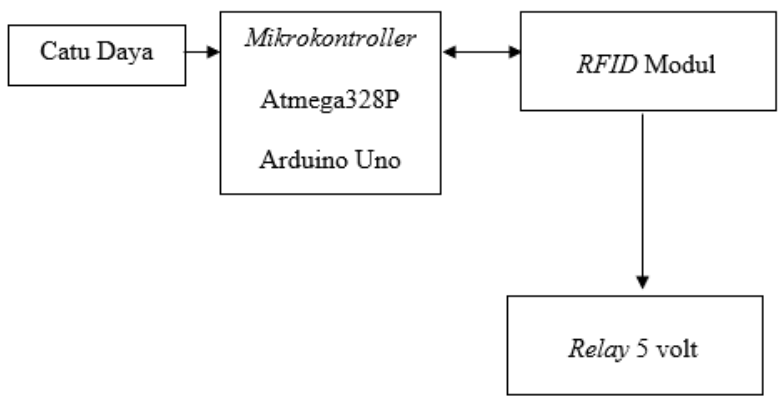

Gambar 7. Blok diagram

Pada gambar di atas memiliki beberapa komponen perangkat keras (hardware)prototype alat pengaman pintu, adalah sebagi berikut :

1. Catu daya merupakan komponen yang berguna unntuk memberikan energy listrik ke rangkaiana yang terdapat dalam sistem.

2. RFID Modul memiliki dua proses utama yaitu proses perekaman e-KTP dan proses identifikasi yang kan disimpan pada mikrokontroler.

3. Mikrokontroler merupakan pusat utama untuk memberikan perintah berupa sebuah IC Mikrokontroler seri ATMega328.

4. Relay 5v merupakan perangkat keras sebagai indikator bahwa motor menyala atau tidak.

\subsection{Cara Kerja Alat}

Prototype alat pengamanan kendaraan bermotor ini dirancang dengan memanfaatkan sensor RFID yang bekerja dengan melakukan proses perekaman dan identifikasi e-KTP dengan pola berbentuk kode digital disimpan dalam chip mikrokontroler ATmega328P.

Cara kerja alat dapat dilihat pada flowchart berikut ini:

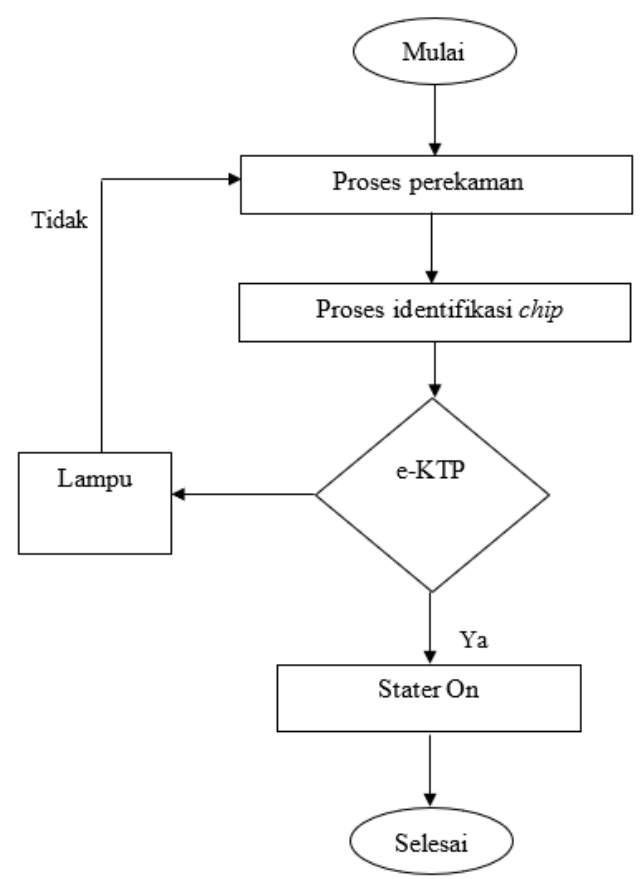

Gambar 8. Flowchart cara kerja alat berikut.

Untuk alur kerja yang dapat digambarkan pada control flowchart diagram di atas yaitu sebagai 
1. Terlebih dahulu melakukan proses perekaman e-KTP yang nantinya disimpan dalam chip mikrokontroler.

2. Proses identifikasi e-KTP apakah e-KTP sesuai atau belum pernah melakukan perekaman sebelumnnya.

3. Jika tidak cocok maka lampu relay berwarnah merah yang artinya bahwasanya e-KTP tersebut belum melakukan perekaman di sistem dan tidak memiliki hak untuk menngunakan bermotor tersebut.

4. Jika proses identifikasi e-KTP sesuai maka hak akses diterima dan stater motor menyala.

\section{HASIL DAN PEMBAHASAN}

Pada bagian ini selanjutnya akan ditujukan pada tahap pembuatan prototype dan simulasi. Dimana sensor RFID akan melakukan proses verifikasi dan identifikasi dengan cara mencocokkan eKTP yang teregristrasi pada system maka sensor akan membaca data pada e-KTP tersebut dan relay akan menyalakan sepeda motor.

\subsection{Rancangan Rangkaian}

Sebelum memulai menjabarkan prosedur kerja pada Arduino Uno, terlebih dahulu penulis akan menjabarkan skema rangkaian dari pembuatan alat penggunaan sistem arduino menggunakan rfid untuk keamanan kendaraan bermotor, dalama proses pembuatan alat ini yaitu dengan menghubungkan Arduino Uno Atmega328P dengan sensor RFID, relay 5 volt, batrai 9 volt, dan kabel jumper.

Adapun skema rangkaian pengaman kendaraan sepeda motor mennggunakan sensor RFID dapat dilihat pada gambar di bawah ini.

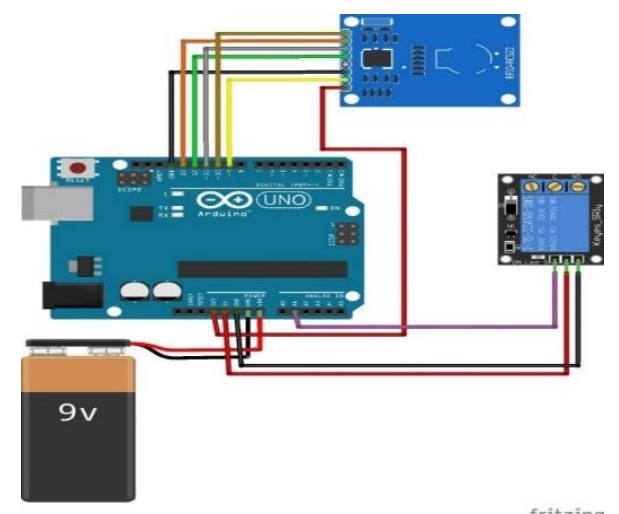

Gambar 9. Rangkaian alat

Dari Skema Rangkaian pada Ganbar 9, instalisasi dan pemasangan Arduino Uno dan beberapa komponen lainnya dengan mengkoneksikan pin di setiap modul pin yang terdapat pada Arduino Uno tersebut, Pin yang saling terkoneksi diatas dapat dilihat sebagai berikut:

1. Pin Gnd Arduino di koneksikan pada GND RFID RC522

2. Pin 13 Arduino di koneksikan pada SCK RFID RC522

2. Pin 12 Arduino di koneksikan pada MISO RFID RC522

3. Pin $\sim 11$ Arduino di koneksikan pada MOSI RFID RC522

4. Pin $\sim 10$ Arduino di koneksikan pada SDA RFID RC522

5. Pin $\sim 9$ Arduino di koneksikan pada RST RFID RC522

6. Pin 3V3 Arduino di koneksikan pada 3.3v RFID RC522

7. Pin 5V Arduino di koneksikan pada GND RELAY

8. Pin GND Arduino di koneksikan pada IN RELAY

9. Pin A1 Arduino di koneksikan pada VCC RELAY

10. Pin VIN Arduino di koneksikan pada + (Plus) Batre

11. Pin GND Arduino di koneksikan pada - (Minus) Batre 
Setelah menghubungkan pin sesuai dengan skema rangkaian, berikutnya yang dilakukan adalah mengupload program yang berbahasa pemrograman $\mathrm{C}++$ yang dituliskan pada software Arduino IDE sehingga alat dapat bekerja sesuai rancangan yang dibuat.

\subsection{Rangkaian Fisik Alat}

Rangkaian fisik alat pengamanan kendaraan bermotor menggunakan e-KTP dan RFID berbasis arduino dapat dilihat pada gambar berikut:

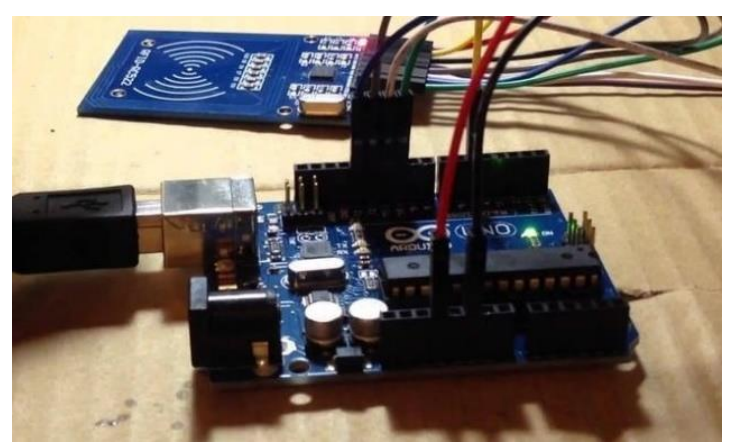

Gambar 10. Rangkaian Fisik alat

\subsection{Pengujian Alat}

Dengan menggunakan alat keamanan kendaraan bermotor menggunakan RFID yang telah penulis buat dari hasil proses pemindaian dan pengidentifikasian e-KTP yang dimaksudkan untuk mendapatkan register tag berupa kode unik yang digunakan untuk menguji kinerja alat pengamanan sepeda motor yang telah dibuat maka alat ini akan membantu dalam peningkatkan keamanan sepeda motor.

Tahap dimulai dari seluruh sistem ini dengan memberikan sumber daya dari batrai 9 volt, dengan adanya arus listrik yang diberikan oleh batrai maka setiap komponen akan mengkonfigurasikan dirinya sendiri. Pada tahap ini memiliki fungsi untuk memastikan agar semua komponen dan sensor dapat berjalan dengan baik sehingga alat dapat menghidupkan sepeda motor sesuai e-KTP yang telah dipindai.

Setelah sistem terlebih dahulu dilakukannya proses pemindaian e-KTP yang mana dari hasil pemindaian tersebut berupa register tag maka kemudian proses selanjutnya adalah pengidentifikasian register tag pada e-KTP dengan register tag yang telah terdaftar pada sistem. Sehingga apabila e-KTP teridentifikasi benar maka relay akan menghidupkan sepeda motor.

\subsection{Prosedur Sistem Kerja}

Di dalam prosedur kerja sistem penulis akan menjabarkan dan memastikan bahwa sistem yang dibuat benar-benar berkerja dengan baik, stabil, dan sesuai dengan rancangan yang telah dibuat. Prosedur kerja sistem yang telah dirancang sebelumnya dapat dilihat pada gambar di bawah ini.

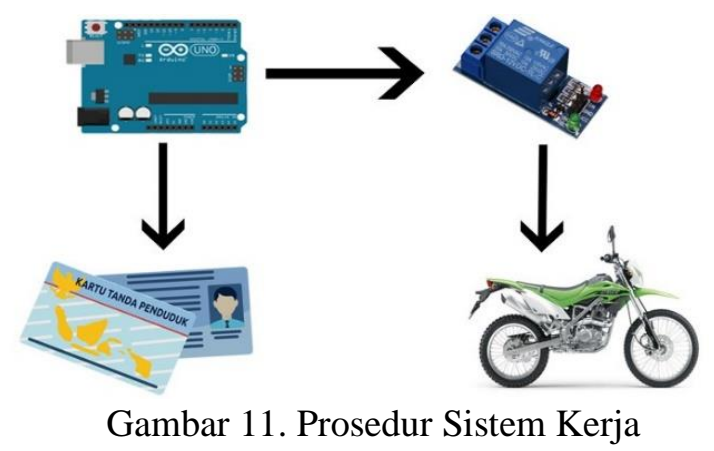

1. Masukan (input)

Agar alat dapat bekerja dibutuhkannya masukan berupa data yang diregistrasikan pada sistem 
supaya pengidentifikasian pada e-KTP dapat berjalan sehingga sepeda motor dapat dihidupkan menggunakan e-KTP yang di-scan ke sensor rfid.

2. Pemrosesan (Procces)

Sensor RFID memiliki dua fungsi utama yaitu proses pemindaian dan proses identifikasi e-KTP, setelah melakukan pemindiaian pada e-KTP yang nantinya register tag yang berupa code digital yang terdaftar pada sistem program Arduino kemudian melakukan proses identifikasi e-KTP jika register tag sesuai maka relay akan menghidupkan sepeda motor atau jika tidak terdaftar maka relay tidak akan menyalakan sepeda motor tersebut.

3. Keluaran (Output)

Pada bagian ini sistem akan memberikan akses kepada pemilik e-KTP yang register tag nya terdaftar pada sistem maka Arduino akan mengirimkan perintah pada relay untuk menghidupkan sepeda motor, jika tidak terdaftar maka relay tidak akan mendapatkan perintah sama sekali.

\section{KESIMPULAN}

Berdasarkan hasil uraian dari bab - bab sebelumnya serta hasil yang dilakukan selama melakukan penelitian dan pengujian alat maka dapat disumpulkam bahwasanya Alat bekerja baik yaitu dengan hanya mengenali e-KTP yang sudah diinputkan ke sistem baik itu hanya 1 maupun lebih dari 1 e-KTP. Jarak maksimal antara alat scanning dan e-KTP adalah $10 \mathrm{~cm}$. Alat pengaktifan sepeda motor ini lebih cepat dalam pengoperasian dibandingkan menggunakan kunci konvensional yaitu sekitar 7 detik. Kekurangan pengaplikasian alat pada sepeda motor adalah alat belum bisa secara otomatis untuk mengunci stang motor.

\section{DAFTAR PUSTAKA}

Abimanyu, D., Anggraini, F., Gunawan, I., \& Parlina, I. (2021). Rancang Bangun Alat Pemantau Kadar pH , Suhu Dan Warna Pada Air Sungai Berbasis Mikrokontroller Arduino Design And Construction Of pH Temperature And Color Monitoring Equipment In Water-Based River On Arduino Microcontroller. 1(6), 235-242.

Ariesta Adhitama Satya Negara, Ufi Najib, J. P. H. (2017). Pemanfaatan E-Ktp Untuk Pengaktifan Sepeda Motor Berbasis Arduino UNO. Jurnal Transistor Elektro Dan Informatika (TRANSISTOR EI), 2(1), 15-20. https://doi.org/10.1007/BF00953962

Baehaki, D. (2017). Sistem Keamanan Pengendali Pintu Otomatis Berbasis Radio Frequency Identification ( RFID ) Dengan Arduino Uno R3. Jurnal Sisfotek Global, 7(1), 35-41.

Isyanto, H., Solikhin, A., \& Ibrahim, W. (2019). Perancangan dan Implementasi Security System pada Sepeda Motor Menggunakan RFID Sensor Berbasis Raspberry Pi. RESISTOR (ElektRonika $\begin{array}{lllll}\text { KEndali TelekomunikaSI Tenaga LiSTrik KOmputeR), } & 2(1), & \end{array}$ https://doi.org/10.24853/resistor.2.1.29-38

Mulya, M. F., Wibawa, Y. E., \& Masalah, A. L. B. (2021). Aplikasi Sistem Personalisasi Dan Monitoring Pengunjung Berbasis Smartcard RFID ( Radio Frequency Identification) Studi Kasus Candi Borobudur. V(September), 1-10.

Saleh, M., \& Haryanti, M. (2017). Rancang Bangun Sistem Keamanan Rumah Menggunakan Relay. Jurnal Teknologi Elektro, UniversitasMercu Buana, 8(2), 87-94. https://media.neliti.com/media/publications/141935-ID-perancangan-simulasi-sistempemantauan-p.pdf 


\section{Halaman Ini Dikosongkan}

